\title{
COR TRIATRIATUM
}

\author{
BY \\ C. G. BARNES AND H. V. L. FINLAY
}

From Hillingdon Hospital, Middlesex

The increasing scope of cardiac surgery in recent years has acted as a great stimulus to the exact diagnosis of congenital heart lesions. A transverse septum almost completely dividing the left auricle into an upper and a lower compartment would appear to be so eminently suitable for surgical treatment that every effort should be made to recognize the abnormality during life. This defect, which has been termed " cor triatriatum," is rare and Parsons (1950), reporting a case, could find only 18 previous examples reported. Andral (1829) was the first observer to mention a heart " with three auricles," while Church (1868) in this country published the first full account of a patient with this condition-a woman, aged 38 . The left auricle was divided by a transverse membranous septum in the upper part of which was a very small elliptical opening.

Parsons (1950) reviewed in detail the theories which have been advanced to explain the nature of this malformation and concluded that " the septum is due to a defect at the junction between the pulmonary veins and the right auricle and is the result of developmental arrest late in the second month of fotal life."

In the hope that a distinctive clinical picture may in time emerge and so allow surgical treatment to be carried out for these patients, a further child is now described who appears to be the first patient with cor triatriatum in whom fluoroscopic and cardiographic investigations have been performed.

\section{Case Report}

C. B., Male infant. Born September 6, 1949. Second child. Birth weight, $8 \mathrm{lb}$. There was no history of infectious illnesses in the mother during the pregnancy, but she had a threatened miscarriage during the third month of gestation.

This child first held his head up at the age of 6 months and sat up at 10 months. He was admitted to hospital in October, 1950, with one week's history of severe cough and increasing tachypnœa. He was severely ill with rapid grunting respirations and movement of the alæ nasi; the temperature was $99 \cdot 6^{\circ} \mathrm{F}$.

The cardiac impulse was felt in the fourth interspace, $1 \frac{3}{4}$ inches from the mid-line. The heart sounds were normal. There was dullness on percussion with diminished air entry over the left base and moist rales at the right apex. The liver edge was felt one finger's breadth below the costal margin in the nipple line. A radiogram of the chest showed patchy consolidation at the left base. W.B.C. $=4250$. $\mathrm{Hb}=10.06 \mathrm{~g}$. per $100 \mathrm{ml}$. The Mantoux reaction was negative at $1 / 1000$. A diagnosis of bronchopneumonia with otitis media was made. This illness was cured by aureomycin; when the child was discharged home on November 9 , the lungs were clear clinically and in the radiogram.

He was readmitted on November 23 with a three day's history of difficult respirations, vomiting, and occasional cough. Physical examination showed an extremely pale child with moderate dyspnoea. The cardiac impulse was now felt in the fifth interspace, $2 \frac{1}{2}$ inches from the mid-line. The heart sounds were rapid but again no murmurs could be detected. There was impairment of percussion note in the left axilla and tubular breath sounds were heard over the right mid-zone behind. Fine inspiratory crepitations could be heard over both lower lobes and in the left axilla. The liver edge was firm and could now be felt fully three finger breadths below the right costal margin. The spleen was not palpable and there was no finger clubbing.

A radiogram of the chest showed some general enlargement of the heart and a diffuse opacity throughout both lung fields. A further course of aureomycin was given and a progress note on December 7 described 
him as "pale, dyspnœic, smiling." Successive radiograms showed an increase in the size of the heart (Fig. 2A). A cardiogram showed sinus rhythm at a rate of 150 per minute. The $P$ waves of $0.3 \mathrm{mv}$. in lead 2 were sharply peaked. There was a right axis shift with QRS complexes splintered and 0.08 second in duration. V leads showed the pattern of right ventricular hypertrophy (Fig. 1). By December 26, puffiness of the eyelids became noticeable and oedema of both feet was present. The tachypnoa was still present and the maximum cardiac impulse was fully three inches from the mid-line.

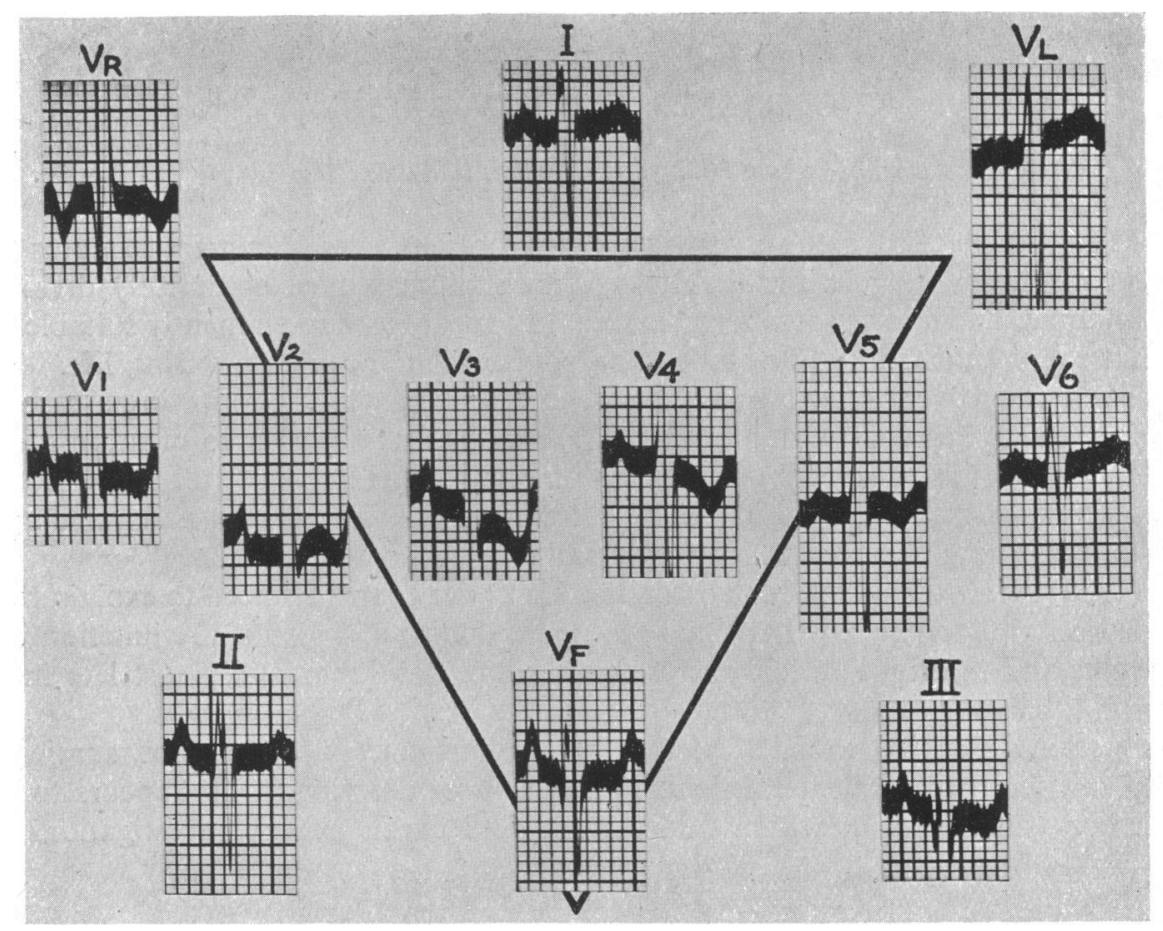

FIG. 1.-Cardiogram, December 13, 1950; showing right ventricular hypertrophy and peaked $P$ waves.

Dr. S. A. Maddocks, reported as follows: "All the diameters of the heart are much increased. There appears to be some relative left auricular enlargement." (A radiogram taken on the same day is reproduced in Fig. 2B.) That the lung changes were entirely congestive was suggested by an E.S.R. of $2 \mathrm{~mm}$. at this time.

On January 5 , at the age of 16 months, the child suddenly died.

\section{POST-MORTEM EXAMINATION}

The post-mortem examination was carried out by Dr. W. H. A. Picton, to whom we are indebted for the use of his notes.

Heart. The anterior surface of the greatly enlarged heart was composed entirely of the right auricle and ventricle with marked prominence of the pulmonary conus. The left ventricle was extremely small and situated entirely behind.

On section, the right auricle was enlarged and the interauricular septum was quite abnormal. It appeared completely smooth and no fossa ovalis, foramen ovale, annulus ovalis or Eustachian valve could be made out. The right auricle communicated with the right ventricle through a tricuspid valve in which the septal and posterior cusps were fused. The cavity of the right ventricle was much dilated and the greatly hypertrophied wall was $8 \mathrm{~mm}$. in thickness. The pulmonary 


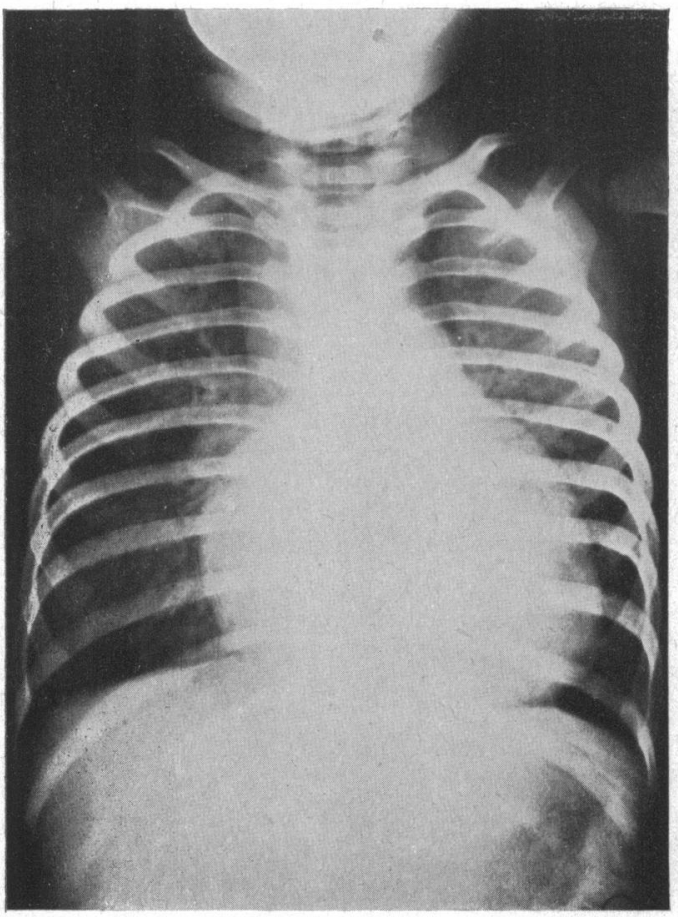

FIG. 2A.-Radiogram of chest, December 7, 1950 ; showing generalized cardiac enlargement with fullness of the left upper border.

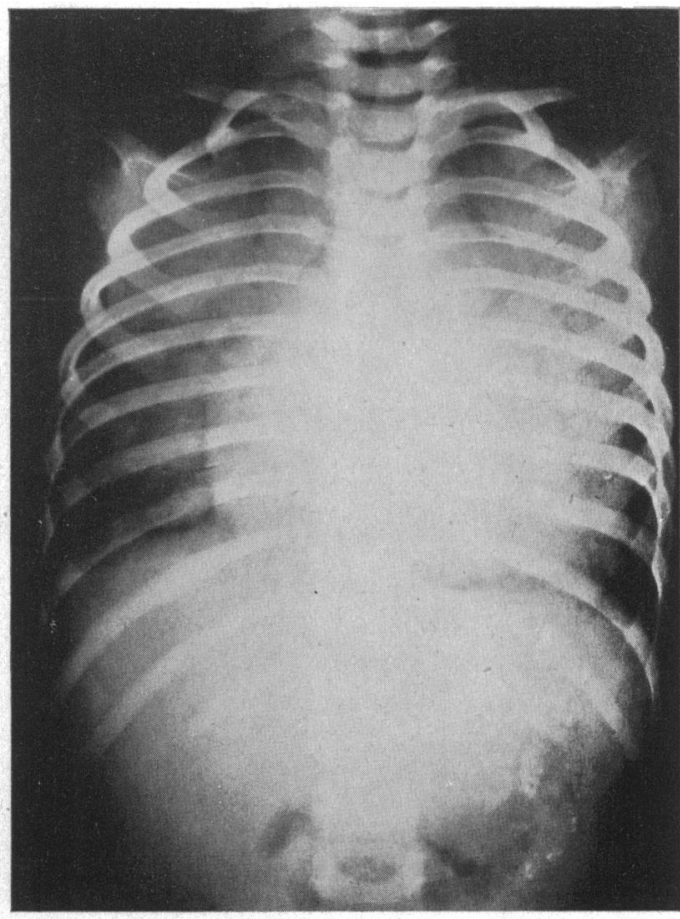

FIG. 2B.-Radiogram of chest, January 3, 1951 ; showing further enlargement of the heart and diffuse opacity of the lung fields due to pulmonary œdema.

trunk, which was much dilated, arose from the right ventricle and the orifice was guarded by three normal semilunar valves.

The left auricle was moderately enlarged and was divided into upper and lower chambers of approximately equal size by a transverse septum (Fig. 3). This septum, concave upwards, was directed downwards and to the right. It was smooth on its upper and lower surfaces, and about four times the thickness of the semilunar valves. In the right and anterior portion of the septum a circular orifice $2 \mathrm{~mm}$. in diameter allowed blood to pass from the upper compartment into the lower. The wall of the upper compartment, into which opened the four pulmonary veins, was pearly white in colour. There was no communication with the right auricle. The wall of the lower compartment was smooth and was continuous with that of the auricular appendix. Again, there was no communication with the right auricle.

This lower compartment opened into the left ventricle through a bicuspid mitral valve which appeared normal in structure and position. The interventricular septum bulged into the left ventricular cavity which, in contrast to that of the right ventricle, was smaller than normal. The maximum thickness of the left ventricular muscle was $6 \mathrm{~mm}$. The aorta arose from the left ventricle. The semilunar valves were normal, the coronary openings were in their normal position, and the ductus arteriosus was closed.

Lungs. All lobes felt rubbery in consistency and cut with increased resistance. The left lower lobe was the seat of bronchiectares.

The other organs were normal apart from congestive changes. A portion of the abnormal septum with the adjoining auricular wall was examined histologically (Dr. H. Rogers) and this showed that the abnormal intra-auricular septum was covered by endocardium, and consisted of collagenous 
tissue in the centre of which there was a band of muscle fibres which appeared to be continuous with those of the auricular wall.

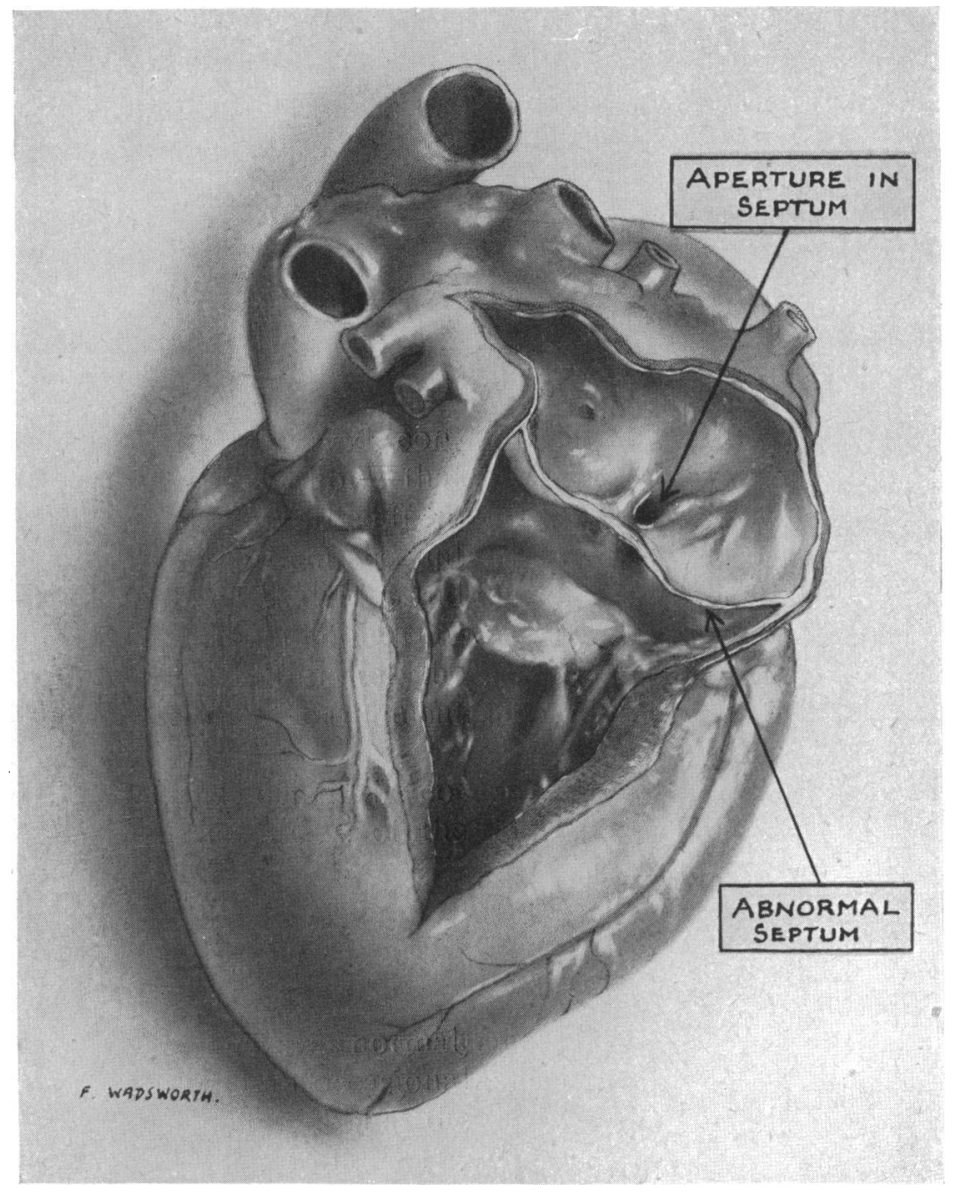

Fig. 3.-Drawing of post-mortem specimen. Posterior view showing interior of left ventricle and left auricle with transverse septum.

\section{Comment}

The remarkable feature of this case was the fact that life continued for 16 months when the only way of entry of the blood from the lungs into the left ventricle was by an opening some $2 \mathrm{~mm}$. in diameter in the centre of the abnormal septum. The symptoms began at the age of 12 months at a time when the child's physical activity increased: his apparent backwardness in development may have been due to his cardiac insufficiency. Had the mechanical obstruction been removed by incision of the septum, complete recovery would probably have occurred. The operation would, in fact, have been simpler than that of valvulotomy as the septum performed no useful function whatsoever and the surgeon would have had no valvular action to preserve.

As Parsons (1950) has stated from his review of the recorded cases, the outstanding clinical feature is respiratory embarrassment secondary to pulmonary congestion, followed by generalized cedema' and enlargement of the liver. These signs, accompanied by progressive enlargement of the heart, are difficult to explain in a patient who does not show the physical signs, radiological appearances, or cardiographic findings of any of the common congenital heart lesions. Indeed, it is 
the very absence of these signs that might suggest the correct diagnosis. The recurrent attacks of pulmonary congestion may mislead one into the erroneous belief that bronchopneumonia with underlying bronchiectasis is the primary lesion and that the cardiac enlargement and failure are secondary.

One might anticipate that the lesion would produce the same symptoms and signs as a tight mitral stenosis and this was the case clinically, with the exception that no murmur was heard. With a heart rate persistently at 150 a minute, the duration of diastole was so short that a diastolic murmur would not have been detected even if it had been present.

\section{Summary}

A further case of cor triatriatum is described. This child appeared to be a case of recurrent bronchopneumonia, and later developed increasing enlargement of the heart with signs of congestive cardiac failure. Death occurred at the age of 16 months. This is believed to be the first case in whom fluoroscopic and cardiographic studies have been carried out.

We are grateful to Professor F. Goldby for his interest in the post-mortem specimen. We are indebted to the medical artist, Miss F. M. Wadsworth, for the drawing of the heart.

\section{REFERENCES}

Andral, G. (1829). Précis d'Anatomie path., Paris.

Church, W. S. (1868). Trans. Path. Soc. Lond., 19, 188.

Parsons, C. G. (1950). Brit. Heart J., 12, 327. 